\title{
A formação profissional frente aos desafios da intervenção e das atuais configurações do ensino público, privado e a distância*
}

\section{The professional background facing the challenges of both intervention and configurations of public, private and distance education}

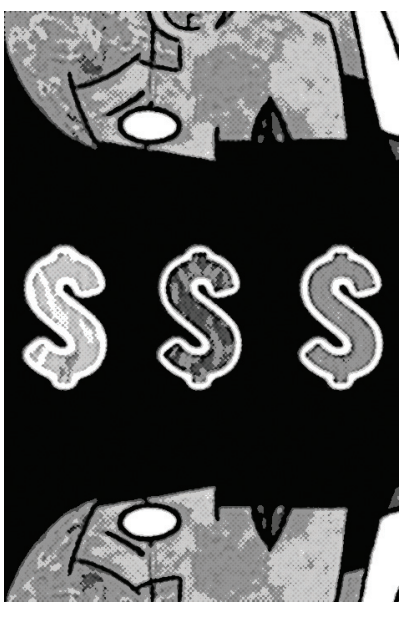

Yolanda Guerra**

Resumo: A crise atual do capital, com suas novas e antigas determinações, impõe metamorfoses ao mundo do trabalho, o que exige um perfil de profissional funcional a essa etapa do capitalismo. Parto da hipótese de que as atuais configurações do ensino respondem às exigências da atual fase do capitalismo e se orienta pelas demandas do mercado de trabalho. Nesta direção, a formação profissional tem um duplo desafio: desvelar e enfrentar a crise do capital e nela as diversas formas de precarização das relações e condições de trabalho, flexibilização dos direitos e focalização das políticas sociais, que, como parte da mesma racionalidade, se expressam e condicionam exercício e formação profissionais.

Palavras chave: Demandas do capital. Configurações do ensino. Mercado de trabalho. Perfil profissional.

Abstract: The current crisis of the capital, together with its new and old determinations, demands
metamorphoses from the world of work, which requires a professional profile that serves to this phase
of capitalism. My hypothesis is that the current configurations of education are adequate to the deman-
ds of the present phase of capitalism, and that such education is guided by the requirements of the

* Este artigo baseia-se na conferência no $3^{\circ}$ Seminário Anual de Serviço Social. O Serviço Social frente aos desafios do século XXI: crise do capitalismo, novos modelos de desenvolvimento e as repercussões na formação e na intervenção profissional, em maio de 2010, promovido pela Cortez Editora.

** Assistente social; mestre e doutora em Serviço Social pela PUC-SP; profa. adjunta da Escola de Serviço Social da UFRJ/Rio de Janeiro/RJ, Brasil; coordenadora do Núcleo de Estudos e Pesquisas sobre o Serviço Social na Contemporaneidade - NEFSSC/UFRJ; atual coordenadora Nacional de Pós-Graduação da Abepss, gestão 2008-10. E-mail: yguerra1@terra.com.br. 
labor market. So, the professional background has a double challenge: to unveil and to face the crisis of the capital, as well as the several ways making the working relations and conditions precarious, the flexibility of rights and the emphasis of the social policies that, as a part of the same reasoning, express and influence the professional activity and background.

Keywords: Demands of the capital. Configurations of education. Labor market. Professional profile.

\section{Introdução}

endo em vista a hipótese acima enunciada, as reflexões preceden-
tes tomam como objeto as determinações do mercado de trabalho
dada a prioridade ontológica deste para desvelar o perfil de profis-
sional que as atuais configurações do ensino público, privado e a distância pretendem formar, visando atender às necessidades do padrão de acumulação vigente.

Porém, não se desvenda a crise do capital e seus desdobramentos, dentre eles a formação de um perfil necessário dadas as configurações do mundo do trabalho, sem uma análise profunda da relação entre crise do capital e capacidade de organização da classe trabalhadora nos diversos espaços geográficos e sócio-ocupacionais e políticos.

Não se explica as atuais configurações do ensino público, privado e a distância se não compreendermos as mudanças no mundo do trabalho e estas como uma condição básica para a elevação das taxas de lucro e do processo de financeirização do capital.

Não se explica a precarização, a redução dos direitos e a reformulação das condições gerais do contrato de trabalho senão com a flexibilização, que é sua forma de aparecer, mas que tem seu fundamento no desemprego estrutural que assola toda a sociedade.

Também não se enfrenta este estado de coisas somente pela sua explicação. Cabe aos sujeitos coletivos socioprofissionais e políticos a busca de estratégias para seu enfrentamento.

\section{A precarização do e no exercício profissional dos assistentes sociais}

Nos últimos vinte anos, como uma tendência que abarca as profissões assalariadas, os assistentes sociais têm seus espaços, condições e relações de tra- 
balho precarizadas e quase totalmente destituídas de direitos. Vivenciam e enfrentam, ao mesmo tempo, as expressões da exploração e dominação do capital sobre o trabalho e efetivam respostas no campo dos direitos, captando e enfrentando as expressões da chamada "questão social", que se convertem, por meio de múltiplas mediações, numa diversidade de demandas para a profissão.

Tais respostas, que não são neutras, dependem de o profissional assumir a sua condição de trabalhador assalariado e do domínio de um referencial teórico-metodológico que os ajude a fazer a leitura mais correta dessa realidade.

Sem dúvida, essa é condição necessária, ainda que insuficiente, para que nossas respostas tenham um grau de eficácia na resistência e enfrentamento da precarização do trabalho e retirada de direitos. Esta configuração do mercado de trabalho e dos espaços sócio-ocupacionais dos assistentes sociais exige determinado perfil de profissional.

Assim, optamos por interpretar o mercado de trabalho dos assistentes sociais e a perda de direitos, inseridos na particularidade histórico-social do capitalismo contemporâneo, num contexto de acirramento da luta de classes, no qual se aprofunda a desvalorização e a superexploração da força de trabalho para a continuidade da reprodução ampliada do capital mediante altíssimos índices de desemprego.

No momento atual, segundo Druck e Filguerias (2007), a hegemonia do capital financeiro, sua volatilidade, rapidez inédita, o curto prazo da especulação financeira contamina toda a sociedade pela pressão do aqui e agora. O trabalhador se torna flexível e descartável, só se produz o que é demandado, naturaliza-se a realidade social e a sociedade não encontra alternativa.

Se essa hipótese tem pertinência, podemos afirmar que um novo perfil do trabalhador se gesta na sociedade sob o domínio do capital financeiro, da sociedade dos imediatismos, do salve-se quem puder, do aqui e agora, da razão instrumental, dos fins que justificam os meios, do presente contínuo e exige capacidade de se adaptar às constantes mudanças e às situações cada vez mais precarizadas.

Todas as análises, quer seja do ponto de vista da sua justificação, quer seja da sua critica, demonstram que tem se mantido no mundo do trabalho aquele trabalhador que se adapta aos processos de precarização e às constantes perdas de qualidade do/no trabalho. Não aquele trabalhador que oferece resistência à precarização e perda de direitos, mas o que apesar delas ainda se mantém. Tem 
se assegurado o trabalhador que se adapta a constantes mudanças no conteúdo do trabalho e aquele profissional que se converte em empresário de si.

Está em curso a gestão de uma nova cultura do trabalho, uma cultura da adaptação às novas normas da sociedade flexível e de um perfil ainda mais adaptativo de trabalhador. Não há dúvida de que o desemprego e a precarização permitem que se transfira para o trabalhador a responsabilidade por sua própria empregabilidade. Temos visto no meio profissional que a corrida dos assistentes sociais para a sua qualificação os leva, em alguns casos, a participar de cursos sem qualidade, aligeirados ou voltados para a habilitação no domínio do instrumental. Como todo trabalhador, o assistente social nas instituições públicas e/ou privadas é submetido (e muitas vezes submete) ${ }^{1}$ aos programas de treinamento, tenham eles conteúdos técnicos ou comportamentais, tendo em vista a conformação de um dado perfil profissional.

Os estudiosos sobre o tema vêm apontando que as determinações atuais da precarização evidenciam:

1) os processos de precarização e a perda de direitos como decorrência da reestruturação produtiva e aplicação dos ajustes neoliberais;

2) que as respostas à crise do fordismo não apenas foram ineficazes como a aprofundou, já que se desenvolveram à base da flexibilização do trabalho e da perda de direitos;

3) o crescimento ou consolidação do trabalho flexível e precário em todas as sociedades e esferas, espaços ocupacionais e profissões. Há uma clara desestabilização de profissões e categorias que eram consideradas estáveis, como, por exemplo, os executivos de empresas; ${ }^{2}$

4) uma relação direta entre precarização e diversas formas de flexibilização do trabalho e dos direitos: como modos contemporâneos de dominação do trabalho (Druck, 2002). Estes só podem ser compreendidos como fenômenos indissociáveis;

1. Refiro-me, especialmente, aos assistentes sociais que desenvolvem programas chamados Gestão de RH, Gestão de Pessoas ou de Desenvolvimento do Capital Humano. Estes, em muitos casos, não se percebem como trabalhadores, e muitas vezes submetem outros trabalhadores ao adestramento visando sua adaptação à organização.

2. Se podemos dizer que a arte imita a vida, o filme baseado em um romance de Donald Westlake, do diretor grego Costa-Gavras intitulado $O$ corte, é exemplar. 
5) que a precarização do trabalho e a flexibilização dos direitos são as mudanças mais visíveis de um período de hegemonia do capital financeiro.

Nesse sentido, a lógica do capitalismo que se aprofunda nesta etapa é a de expulsar o trabalho vivo do processo de trabalho como estratégia de valorização do capital. Nesta lógica, uma massa de trabalhadores tem pouca ou quase nenhuma chance de inserir-se novamente no circuito do grande capital, restando-lhes apenas as ocupações aleatórias (Alves, 2000, p. 76).

Também faz parte dessa lógica o predomínio do capital financeiro (Chesnais, 1996). O capital tem seu ciclo encurtado, constituindo uma nova dinâmica na relação espaço/tempo (Harvey, 1994), surgindo uma camada da burguesia de caráter essencialmente rentista, pois seus ganhos são resultantes de transferências da esfera da produção e da troca.

Assim, pode-se dizer que as respostas contemporâneas do capital à sua crise visam a retomada das taxas de lucro, mas não é só isso: visam fragilizar a organização dos trabalhadores e aprofundar o controle sobre elas.

Para tanto, há o empenho na retirada de direitos que recebe o nome de flexibilização.

Com o exercício profissional dos assistentes sociais não poderia ser diferente. Este tem na flexibilização uma forma de precarização do seu trabalho tanto como segmento da classe trabalhadora quanto como profissional que atua no âmbito dos serviços, das políticas e dos direitos sociais. A precarização do exercício profissional se expressa por meio de suas diferentes dimensões: desregulamentação do trabalho, mudanças na legislação trabalhista, subcontratação, diferentes formas de contrato e vínculos que se tornam cada vez mais precários e instáveis, terceirização, emprego temporário, informalidade, jornadas de trabalho e salários flexíveis, multifuncionalidade ou polivalência, desespecialização, precariedade dos espaços laborais e dos salários, frágil organização profissional, organização em cooperativas de trabalho e outras formas de assalariamento disfarçado, entre outras.

Essas características marcam os espaços laborais dos assistentes sociais, ainda que de formas, níveis e graus distintos, segundo a sua inserção diferenciada e diferentes condições sócio-ocupacionais.

Comparece hoje nos espaços laborais do assistente social o crescente aumento de profissionais que possuem mais de um vínculo de trabalho, o que caracteriza o pluriemprego, bem como se observa a inserção socioprofissional 
em duas ou mais políticas sociais, rotatividade no emprego, instabilidade e insegurança, jornada de trabalho extensa (cumpre carga horária de mais de dez horas diárias de trabalho), além do sobretrabalho ao qual a mulher encontra-se submetida.

Temos ainda a tendência à terceirização do trabalho, travestida da forma de assessoria. Nessa tendência, os profissionais são estimulados a se organizar em cooperativas multiprofissionais de prestação de serviços, seja para elaborar projetos, para o que busca cursos rápidos e destinados apenas à instrumentação imediata; seja nas diversas áreas, como saúde, empresas e previdência privada, prestando serviço de atendimentos multidisciplinares em entidades públicas, hospitais e, ainda, promovendo cursos e treinamentos em diversas áreas. Outras vezes são contratados por associação de moradores com recursos repassados pelo Estado, dentro do marco legal do terceiro setor. Claro está que não possuem nenhum direito à proteção social pública.

Outra tendência forte é o chamado empreendedorismo, que cada vez mais se configura como forma oculta de trabalho assalariado e que permite a proliferação das distintas formas de flexibilização salarial, de horário, de funções ou forma de contratação. ${ }^{3}$

Uma clara consequência das distintas formas de contratação é a fragmentação da categoria e desagregação profissional. Isto ocorre porque dentro de um mesmo espaço laboral os profissionais são contratados sob modalidades diversas, com salários diferentes para realizar, em muitos casos, atividades similares.

A crescente segmentação do mercado de trabalho estabelece uma diferenciação nas condições de trabalho nas instituições estatais e nas da iniciativa privada, alterando atribuições e papéis. ${ }^{4}$

Estas variadas modalidades de contratação dos seus serviços reduzem a capacidade dos profissionais de contraposição a essa lógica, de questionar os objetivos institucionais e de potencializar as contradições inerentes às relações sociais capitalistas.

A exigência do cumprimento de metas quantitativas leva a uma queda na qualidade dos serviços prestados, acirrando a competição entre profissionais

3. Tem sido cada vez mais recorrente a contratação de assistentes sociais sob outra denominação ou como aborda a Resolução n. 572/2010, do CFESS, sob a nomenclatura de cargos genéricos.

4. Exemplo da distinção nas condições de trabalho nos espaços públicos e privados é o caso da docência em Serviço Social. 
bem como a um maior desgaste físico e mental, já que nessa forma de remuneração priorizam-se os esforços individuais dos profissionais. ${ }^{5}$

A descontinuidade no/do exercício profissional, já que muitos trabalham em regime de plantão, incentiva intervenções pontuais, de caráter eventual, visando respostas imediatas, sem continuidade. Essa descontinuidade não permite a apreensão do processo no qual o exercício profissional se realiza, limitando o conhecimento da totalidade dos elementos que constituem a situação.

A exponenciação das expressões da chamada questão social faz com que sejam tratadas não apenas como questão moral, mas criminalizadas e punidas.

Condicional ao modo de intervir nas manifestações da questão social é a identificação do pobre como perigoso, transgressor, sujeito à repressão e extinção. Igualmente, é possível identificar o crescimento de práticas autoritárias e cerceadoras de direitos, que tentam preencher os espaços deixados pelas políticas públicas por meio da refilantropização da questão social e da assistencialização das políticas sociais, ou mesmo reduzir a "solução" dos problemas sociais a intervenções individualizantes, formais e burocráticas.

A negação do direito do usuário aparece nas práticas desenvolvidas como "conferente da pobreza", no caso da atribuição do assistente social no Benefício de Prestação Continuada (BPC). Nota-se que o assistente social nesse programa tem sua atribuição restrita, em muitos casos, a administrar o BPC.

Por se tratar de um exercício profissional que atua nas expressões da chamada questão social, que se manifesta no cotidiano da vida dos usuários dos serviços sociais e das políticas sociais, nossa intervenção não desvela seus fundamentos. Ao contrário, na imediaticidade do cotidiano, dadas as suas características estruturadoras, a tendência é de considerar a intervenção pelo seu resultado, sem buscar os seus fundamentos e de realizar intervenções que concebam o indivíduo isolado da estrutura e contexto sócio-histórico, de modo a responsabilizá-lo, e mais ainda, a culpabilizá-lo pelo seu suposto sucesso ou fracasso, com o que subverte-se princípios e diretrizes da formação profissional.

Não é casual que nesta conjuntura apareçam novas demandas de intervenções pontuais, autonomizadas e isoladas junto às famílias, práticas terapêuticas, ações de responsabilidade individual e/ou social, requisições de práticas clínicas.

5. No âmbito da formação, alguns coordenadores de curso de Serviço Social em universidades e/ou centros universitários têm seus salários proporcionais ao número de alunos matriculados nos cursos. 
Ora, o contexto que vivemos é propício aos apelos aos subjetivismos, adaptação de comportamentos, amenização de conflitos, como se os resultados fossem decorrência da mera vontade do sujeito. Com isso, nem sempre o profissional percebe a incompatibilidade entre os objetivos institucionais e os profissionais, e, sobretudo, com os princípios do projeto ético-politico profissional.

Tais elementos vêm implicando a emergência de novas demandas para o Serviço Social e a necessidade de redimensionar a formação profissional.

Não é demais lembrar que neste quadro aprofunda-se a alienação do trabalho e aumenta a exploração.

Muito raramente a literatura produzida no Serviço Social se debruça sobre as consequências geradas pela degradação das condições de trabalho e vida dos assistentes sociais. Por vezes, as ações repetitivas, rotineiras e acríticas, os imediatismos, a fragmentação do trabalho, a urgência em dar respostas, a necessidade de buscar soluções individuais, sendo responsabilizado pelo seu sucesso ou fracasso, acarreta doenças profissionais, submetidos que estão à pressão para resolver os problemas que requisitam respostas imediatas e urgentes.

Neste contexto, a insatisfação no que se refere às condições e relações de trabalho produz sofrimento e desgaste emocional, a exemplo dos assistentes sociais do campo sociojurídico, especialmente do sistema penitenciário. ${ }^{6}$

A supressão da noção de direitos das políticas sociais tem potencializado não apenas seu caráter assistencialista e mercantilista. De um lado, o atendimento focalizado da pobreza absoluta através de programas de transferência de renda/assistenciais; ${ }^{7}$ de outro, a mercantilização das políticas sociais transformando usuários em consumidores dos serviços sociais mercantis. ${ }^{8}$ Porém, outra forma de intervenção vem caracterizando o Estado neoliberal na atualidade. É

6. Desconheço estudos sobre o adoecimento no trabalho do assistente social. Não obstante, uma análise empírica nos permite afirmar que se trata de importante questão a ser investigada. No que se refere ao trabalho docente, um interessante estudo foi realizado por Denise Vieira da Silva Lemos, na sua tese de doutoramento Alienação no trabalho docente? O professor no centro da contradição, defendida no âmbito do Programa de Pós-Graduação em Ciências Sociais da UFBA.

7. Chamo a atenção para a falta de recursos para o desenvolvimento dos programas/políticas sociais de caráter redistributivista e compensatório, considerando que a prioridade do governo (sob a recomendação dos organismos multilaterais) é a de diminuir a pobreza absoluta, para o que são criados programas focalistas restritivos ao enfrentamento da pobreza.

8. A política de educação é hoje a maior referência desse processo de mercantilização das políticas sociais. 
o que Loïc Wacquant denomina de Estado policial penitenciário, o qual vai substituindo o chamado Estado social. Diz ele:

A penalidade neoliberal apresenta o seguinte paradoxo: pretende remediar com um "mais Estado" policial e penitenciário o "menos Estado" econômico e social que é a própria causa da escalada generalizada da insegurança objetiva e subjetiva em todos os países, tanto do Primeiro como do Segundo Mundo. (2001, p. 7)

E aqui no Terceiro Mundo, então, nem se fale! A criminalização da pobreza como forma de apoiar o novo regime do assalariamento precário e mal remunerado obedece, segundo este autor, aos seguintes objetivos:

Em primeiro lugar, o sistema penal contribui diretamente para regular os segmentos inferiores do mercado de trabalho - e isso de maneira infinitivamente mais coercitiva do que todas as restrições sociais e regulamentos administrativos. Seu efeito aqui é duplo. Por um lado, ele comprime artificialmente o nível do desemprego ao subtrair à força milhões de homens da "população em busca de um emprego" e, secundariamente, ao produzir um aumento do emprego no setor de bens e serviços carcerários, setor fortemente caracterizado por postos de trabalho precários. (2001, p. 96)

O que se pode apreender da maneira como a chamada questão social está sendo enfrentada é que o Estado, paralelamente à assistencialização das políticas sociais, de um lado, e da mercantilização e privatização, do outro, adota medidas repressivas de criminalização da pobreza e dos movimentos sociais. ${ }^{9}$

Importa-nos destacar que, como foi tratado até o momento, combinam-se perfeitamente precarização do trabalho, flexibilização da legislação trabalhista (e dos direitos sociais) e políticas sociais focalizadas, reduzidas a programas de combate à pobreza, o que vem reforçar a hipótese inicialmente apresentada de que essas formas de precarização são regidas pela mesma lógica, qual seja, do curto prazo, das resoluções imediatas, das intervenções pontuais e precárias. Caracteriza-se pela lógica instrumental que subordina os processos sociais ao reino da volatilidade e do aqui e agora.

9. O Rio de Janeiro é o caso emblemático dessa situação. Para além dos programas denominados Tolerância Zero e Choque de Ordem, surgem recentemente as chamadas Unidade de Policiamento Pacificadora (UPPs), os muros ecológicos, como expressão de segregação e forma de controle/administração da chamada questão social, que é "tratada", reincidentemente, como caso de polícia. 
Outra sorte não poderia seguir a formação profissional diante dessa conjuntura marcada pelo aumento do desemprego, da precarização e flexibilização do trabalho e da adoção de um modelo de políticas sociais sem direitos sociais (Vieira, 1997).

O novo padrão de produção, resultante do enfrentamento do capitalismo à sua crise mais profunda, impõe novas configurações na relação público/privado, de modo que o formato da educação superior no Brasil prescinde da análise dessa relação. Os novos traços que marcam a educação são expressão do movimento do capital rumo à recuperação de sua taxa de lucro.

Pode-se observar que as novas modalidades de produção e reprodução do capital se expressam na particularidade prático-profissional do Serviço Social em suas diversas dimensões, a exemplo do mercado de trabalho profissional. São modalidades que passam a exigir a reciclagem de procedimentos operativos e também determinam novas requisições técnicas, éticas e políticas, ou seja, constituem diferentes demandas para a profissão.

Que tipo de formação profissional combina-se com tais necessidades, processos e tipo de Estado e quais as atuais configurações do ensino público, privado e a distância é o tema que trataremos a seguir.

\section{Atuais configurações do ensino e perfil profissional}

$\mathrm{Na}$ lógica que estamos evidenciando e diante das atuais necessidades do capital, o trabalhador deve portar as seguintes características: ser desespecializado, desregulamentado, polivalente e multifuncional. É chamado a desenvolver várias competências e habilidades voltadas ao mercado, portador de valores individualistas e imediatistas, a partir dos quais vale o ter (neste caso, o certificado) em detrimento do ser (neste caso, um profissional qualificado), de formação aligeirada, mas que the garanta competitividade e capacidade de se adaptar a esses novos e difíceis tempos.

Prioriza-se a formação que atenda as orientações do Banco Mundial, sendo que democratizar passa a ser sinônimo de uma inserção, ainda que precarizada, em instituições de ensino, seja pública ou privada, daí ser a expansão de vagas a meta cobrada pelos organismos internacionais.

Como aponta a maior parte dos analistas sobre a educação, no período ditatorial ampliou-se significativamente o número de vagas para a educação 
superior no país, principalmente pela expansão das universidades federais e por uma extensa gama de incentivos à iniciativa privada. Com Fernando Henrique demarca-se a expansão do setor privado empresarial. Atualmente, há uma larga hegemonia do setor privado no que concerne aos cursos de graduação. Por outro lado, a pós-graduação stricto sensu encontra-se majoritariamente em instituições públicas e financiadas por agências estatais. Em princípio, por meio de uma análise rápida e superficial da situação, parece haver uma incoerência entre a exigência de excelência do sistema da pós-graduação stricto sensu e a mediocrização do ensino na formação graduada. Mas essa ambiguidade é mera aparência, já que ambos estão submetidos à lógica do mercado e aos interesses do empresariado.

Com a reforma do Estado, que se dá no governo FHC, realizada pela mão de ferro do ministro Bresser Pereira, ${ }^{10}$ e não casualmente chamada de contrarreforma, a universidade passa a ocupar o âmbito dos serviços não exclusivos do Estado. ${ }^{11}$

O significado disso é que, juntamente com hospitais, centros de pesquisas, museus, a educação: "a) [...] deixou de ser concebida como um direito e passou a ser considerada um serviço; b) [...] deixou de ser considerada um serviço público e passou a ser considerada um serviço que pode ser privado ou privatizado $^{12}$ (Chaui, 2003).

A atual configuração do ensino, segundo Marilena Chaui, visa transformar a universidade que é tradicionalmente uma "instituição social" voltada para a universalidade, ou seja, tem a sociedade e seus valores como referência, e a produção é qualificada sob critérios da sua relevância social, em uma organização social. Ao ser convertida em organização social, essa universidade

10. Lembro que para encaminhar a reforma do Estado, FHC criou o Ministério da Administração Federal e Reforma do Estado (Mare), tendo à frente o ministro Luís Carlos Bresser Pereira.

11. Importa-nos enfatizar os serviços não exclusivos do Estado, dentre os quais os hospitais, as universidades, os serviços sociais, assistenciais e de saúde. Estes são os serviços que, segundo Bresser Pereira (1986, p. 283), "o Estado realiza e/ou subsidia porque os considera de alta relevância para os direitos humanos, ou porque envolvem economias externas, não podendo ser adequadamente recompensadas no mercado por meio da cobrança dos serviços".

12. Fica evidente, nas palavras do ministro, a concepção que orientou a "contrarreforma" do Estado no Brasil: "reformar o Estado significa transferir para o setor privado as atividades que podem ser controladas pelo mercado" (Bresser Pereira, 1996, p. 11), de modo que o Estado passa a ser um regulador e repassador de recursos. 
torna-se referência de si mesma. Orientada pela lógica de mercado, valoriza o quanto se produz, em quanto tempo e qual o custo do que é produzido.

As características das organizações sociais, entre elas a imprevisibilidade, compõe o perfil de profissional adequado e funcional ao contexto sócio-histórico.

Não é demais evidenciar que esse modelo de Estado incorpora a racionalidade racionalista do mercado, orientada pelos "valores de eficiência e qualidade na prestação de serviços públicos e pelo desenvolvimento de uma cultura gerencial nas organizações" (Bresser Pereira, 1996, p. 15).

Outro elemento que nos ajuda a reconhecer a chamada universidade operacional, é que ela é gerida pela racionalidade do mercado e administrada por contratos de gestão mantida por fundações. Alguns autores (entre eles Silva Jr. e Sguissardi, 1999 e Leher, 2004) por meio de pesquisas trataram de demonstrar a vinculação entre nossa política educacional e o receituário dos organismos multilaterais (FMI, Bird, Banco Mundial, entre outros).

No governo Luís Inácio Lula da Silva, o Plano de Mobilização Social pela Educação (PMSE), lançado em maio de 2008, é emblemático da direção do ensino seja no nível médio, seja no superior. Propõe a promoção de atividades que contribuam para a melhoria da qualidade da educação por meio do chamamento à comunidade. Solicita a realização de atividades por voluntários que aproximem escola e comunidade, campanhas de conscientização e incentivo aos membros da comunidade para integração às ações voluntárias de mobilização.

Segundo Otranto (2006),

os fundamentos da reforma da educação superior do governo Lula estão calcados em marcos regulatórios defendidos pelos organismos internacionais. A maior parte desses fundamentos foi defendida no documento elaborado pelo Grupo de Trabalho Interministerial e direcionou medidas legais que foram sendo implantadas, desenhando a reforma de acordo com os interesses governamentais. Dentre estas medidas pode-se destacar o Prouni, o Sinaes, a Lei de Inovação Tecnológica, as Parcerias Público-Privadas, o decreto que normatiza a educação a distância, além das medidas já adotadas para a educação profissional.

Do que nos cabe mencionar, dada a relação com a formação profissional dos assistentes sociais brasileiros, dentre as diretrizes adotadas pelo governo atual, três merecem destaque especial: a) o financiamento público do ensino 
universitário privado e a expansão desmesurada de vagas (Prouni e Reuni); b) o aumento no número de alunos e a educação a distância; c) o Sistema de Avaliação - Sinaes e a avaliação trienal — Capes.

No que se refere ao primeiro item, dois programas serão brevemente referidos: o Programa Universidade para Todos (Prouni) e o Programa de Apoio a Planos de Reestruturação e Expansão das Universidades Federais (Reuni).

O Prouni, criado pelo governo Lula em 2004, que visa a atender as universidades privadas, tem como finalidade a concessão de bolsas de estudo (integrais ou parciais) não apenas em cursos de graduação, mas também em cursos sequenciais. As instituições de ensino superior privado que aderem ao programa recebem isenção de tributos.

Para a manutenção do Prouni, e com o objetivo de financiar bolsas de estudos, já que devem ser ocupadas as vagas ociosas no sistema privado, o governo institui o Fundo de Financiamento ao Estudante de Ensino Superior, o qual tem duas modalidades: 1) a fiança solidária: os candidatos a esse tipo de financiamento se associam a grupos de três a cinco estudantes que se tornam fiadores entre si. Isentos da necessidade de comprovação de renda, os participantes se responsabilizam mutuamente pelo pagamento das prestações de todos os integrantes do grupo; e 2) a fiança tradicional, ou seja, a garantia dada por fiadores habilitados junto à Caixa Econômica Federal, que é o agente financeiro do fundo.

Está clara a funcionalidade dessas ações "solidárias" no contexto da hegemonia do capital especulativo, rentista, parasitário e, em especial, como estratégia de ocupação das vagas ociosas das universidades (ou centros universitários) privadas.

Dotar as universidades federais das condições necessárias para a ampliação do acesso e a permanência dos estudantes na educação superior é o principal objetivo do Programa de Apoio a Planos de Reestruturação e Expansão das Universidades Federais (Reuni).

Sobre esse programa, convém considerar que o governo vem promovendo a expansão de vagas sem a devida infraestrutura necessária e, em alguns casos, sem provimento de concursos públicos para docentes e pessoal técnico-administrativo, gerando sérios problemas, tais como: salas superlotadas, falta de espaço físico adequado e de carteiras para os alunos, aumento da carga horária docente e da exploração da sua força do trabalho, preocupação restrita ao atendimento de metas de produtividade em detrimento da qualidade. 
De acordo com o documento "Expansão das Ifes: nota pública do Andes-SN", ao final de cinco anos, a meta é alcançar uma taxa de conclusão média de $90 \%$ nos cursos de graduação presenciais e uma relação de dezoito alunos por professor na sala de aula.

É dentro dessa lógica de precarização e a banalização da oferta que surgem os cursos a distância, que não se destacam pela utilização de novas tecnologias, senão pelo uso de material sucateado e de má qualidade, comprometendo inteiramente o perfil de profissional que se deseja. $\mathrm{O}$ ensino a distância oferecido pelas universidades privadas são os novos nichos de mercado cobiçado por empresários de vários setores nacionais e estrangeiros.

Além disso, uma estratégia que várias universidade privadas tem se utilizado é a flexibilização permitida pelo MEC de até $20 \%$ da carga horária ministrada a distância. ${ }^{13}$

Ocorre que as universidades têm tornado "fábricas de diplomas", e se há fábricas de diplomas é porque existem compradores. Como dito, é necessário forjar um perfil de estudante adequado a essa lógica de banalização, aligeiramento e precarização do ensino e da educação superior.

Nem é preciso dizer que essas estratégias se confrontam com os princípios básicos da nossa formação profissional centrados na qualidade, rigorosidade, publicidade e gratuidade.

Também é importante dizer que a formação é um espaço de trabalho do assistente social que recebe impacto dessa conjuntura e a impacta, responde e resiste a ela.

O trabalho docente em instituições privadas tem como características os contratos temporário, a insegurança, a instabilidade, a rotatividade, o assédio moral por parte de patrões e até de alunos, a redução dos encargos trabalhistas, a desresponsabilização dos empregadores pelo pagamento dos direitos trabalhistas, a exemplo do fundo de garantia do tempo de serviço (FGTS), a ausência da contribuição previdenciária, décimo terceiro salário, férias. Ainda mais,

13. Fazendo parte desta mesma lógica, o governo Lula implementa o projeto Universidade Aberta do Brasil, que se constitui no maior sistema nacional de educação superior a distância ( 830 polos). Dele participam instituições públicas de educação superior que, em parceria com estados e municípios, investem na formação dos professores da educação básica pública. 
de um modo geral, o valor da remuneração do trabalho pago aos professores não leva em conta as titulações acadêmicas, nivelando-os por baixo, tudo com amparo legal. ${ }^{14}$

A observação empírica nos mostra que a precarização do trabalho docente nas universidades públicas, por exemplo, que vem se acentuando, se manifesta em ritmos, grau e intensidade diversos que a precarização nas universidades privadas e/ou comunitárias. Apesar da precarização que caracteriza as universidades privadas, no Serviço Social em especial, mas não exclusivamente, elas vêm se constituindo em mercado de trabalho em expansão.

Chaui (1999) faz critica à nova configuração da educação universitária. Diz ela:

Na linguagem do Ministério da Educação, "flexibilizar" significa: 1) eliminar o regime único de trabalho, o concurso público e a dedicação exclusiva, substituindo-os por "contratos flexíveis", isto é, temporários e precários; 2) simplificar os processos de compras (as licitações), a gestão financeira e a prestação de contas (sobretudo para proteção das chamadas "outras fontes de financiamento", que não pretendem se ver publicamente expostas e controladas); 3) adaptar os currículos de graduação e pós-graduação às necessidades profissionais das diferentes regiões do país, isto é, às demandas das empresas locais; 4) separar docência e pesquisa, deixando a primeira na universidade e deslocando a segunda para centros autônomos. (Chaui, 1999, p. 6)

Como traçado pela chamada reforma do Estado e no marco legal que a ampara, está em curso uma nova regulação das políticas educacionais. Muitos são os fatores que indicam isso, dentre os quais possível destacar a centralidade atribuída à administração escolar, elegendo a escola como núcleo do planejamento e da gestão; a regularidade e a ampliação dos sistemas de avaliação (Sinaes e Coleta Capes), a educação dirigida à formação para o trabalho e a educação orientada para a gestão ou controle da pobreza.

14. No Serviço Social, o caso emblemático e que merece ser objeto de denúncia e crítica é o da PUC-SP. O curso que é o pioneiro na formação dos assistentes sociais brasileiros, que tem sido responsável pela qualificação de grande parte da intelectualidade brasileira e que protagonizou a reformulação do currículo em 1982, operando uma inflexão na formação profissional, está sucateado. Seus docentes, intelectuais renomados no Brasil e na América Latina, estão sendo pressionados a se retirar, alguns pela via da aposentadoria e outros pela demissão (in)voluntária. 
Com isso tem havido uma mudança na concepção de docência, na lógica do curto prazo ela é vista como habilitação rápida para graduados que precisam entrar rapidamente no mercado de trabalho.

No que se refere à avaliação do ensino em nível da graduação, o Sinaes engloba a avaliação das instituições de ensino superior, dos cursos de graduação e do desempenho dos estudantes. O Sinaes, além de servir para que os cursos de graduação obtenham seu credenciamento, autorização e reconhecimento, ${ }^{15}$ se propõe a avaliar o desempenho dos estudantes por meio do Enade. ${ }^{16}$ Segundo vários analistas da educação superior no Brasil, especialmente Otranto (2006), "o Sinaes atinge, então, o seu objetivo de regular e ajustar a educação superior brasileira às exigências de avaliação inseridas nos documentos emanados dos organismos internacionais, de forte cunho quantitativo e competitivo entre as instituições".

Quanto à avaliação da pós-graduação, tem havido mudanças significativas no seu direcionamento com a introdução do Qualis Periódico e em algumas áreas (entre elas o Serviço Social) do Qualis Livro. Para tanto, as comissões de área foram chamadas a atribuir critérios de avaliação de revistas acadêmicas e livros, classificando-os em termos de Qualis. ${ }^{17} \mathrm{O}$ Qualis e seus critérios têm sido objeto de críticas e questionamentos por parte da comunidade científica.

As comissões vêm perdendo sua pouca autonomia no que se refere à proposição de critérios que contemplam as particularidades da área. Tais critérios são formulados por assessores da Capes e formatados numa ficha de avaliação única para todas as áreas acadêmicas. Cada vez mais a avaliação é equalizada, burocratizada, uniformizada, descaracterizada, suprimindo as diferenças entre as áreas.

Sem dúvida a atribuição de peso orienta-se pela lógica que valoriza a produção bibliográfica de docentes e discentes e a redução do tempo médio para

15. Esta avaliação é realizada por avaliadores da área, profissionais que espontaneamente se cadastram no Inep tendo em vista a visita in locu nas instituições de ensino para averiguar o cumprimento de determinados critérios presentes na avaliação. Todo esse processo tem sido amplamente criticado, porém o mais sério é que raras vezes a pontuação da ficha de avaliação determina o fechamento do curso e mesmo quando isso ocorre, o avaliador perde o controle sobre o resultado da sua avaliação, não lhe sendo informado se a sua recomendação foi ou não observada pelo curso.

16. O Enade tem sido não apenas motivo de questionamento, devido à lógica individualista, ao modelo classificatório e hierarquizante que, no limite, culpabiliza os sujeitos, mas também objeto de boicote dos estudantes de Serviço Social e de outras áreas.

17. O indicador Qualis visa atribuir extratos de qualidade da produção dos programas de pós-graduação. 
a titulação de mestres e doutores. Uma característica da atual configuração das pós-graduações é que elas se consolidam medindo e renumerando a qualidade do trabalho pela quantidade de produtos: artigos, livros, projetos, patentes, aulas ou papers. Esse sistema inverte a lógica da formação de qualidade, priorizando e premiando os que investem na acumulação de declarações e certificados em detrimento dos que investem na formação de profissionais e pesquisadores. Assim, vemos que a lógica da avaliação valoriza mais a produção em pesquisa do que atividades de ensino, assim como a redução do tempo médio para a titulação de mestres e doutores. É a lógica da contagem de "quantos entram e quantos saem" nos programas de pós-graduação.

Além disso, o registro da produção ocupa tanto o tempo do docente que pouco lhe sobra para fazer pesquisa, para preparar bem as aulas, para dar boas orientações. Faz-se tudo isso à custa de assumir um sobretrabalho como decisão individual e de enorme desgaste físico e mental. São os resultados quantitativos que orientam a distribuição de recursos: trata-se da política de "mais alunos, com menos recursos".

A esse respeito Chaui (1999) assevera:

O aumento insano de horas-aula, a diminuição do tempo para mestrados e doutorados, a avaliação pela quantidade de publicações, colóquios e congressos, a multiplicação de comissões e relatórios etc. Virada para seu próprio umbigo, mas sem saber onde este se encontra, a universidade operacional opera e por isso mesmo não age.

A pós-graduação lato sensu que, sem dúvida, é o caminho para qualificar a formação permanente, tem sido também a porta de entrada para a privatização.

Além de ser uma forma de complementar os salários dos professores, passa a ser fonte de recursos para pagamento de bolsistas que ocupam lugar do pessoal técnico-administrativo.

Os mestrados profissionais, cuja lógica de "autossustentabilidade" também aponta para importante nicho de mercado, vêm aligeirando a formação de pós-graduação. Conforme expresso nos seus objetivos, tem se constituído em forma de articulação integrada entre universidade e mercado, visando agregar competitividade e aumentar a produtividade em empresas, organizações públicas e privadas (MEC, Portaria Normativa n. 7, 2009). Acentua-se na educação a lógica instrumental, pragmática, aligeirada, competitiva, individualista. Com 
isso, o mestrado profissional ganha força, uma vez que pode ser mais fácil, mais rápido e, em algumas instituições, até sem exigência de defesa de dissertação.

\section{Formação profissional: conquistas e desafios}

A condição de mercadoria barata a ser consumida rapidamente, à qual a formação profissional tem sido submetida, e a constituição de novos nichos de mercado afetam em especial cursos relativamente baixo, como o de Serviço Social. Não é casual que a oferta de cursos a distância encontre no Serviço Social campo fértil.

As entidades da categoria (CFESS, Abepss e Enesso) têm enfrentado criticamente a lógica instrumental da universidade operacional, conforme considera Marilena Chaui, acrescida, nesses novos tempos, da cultura do produtivismo e da avaliação, esta moldada por técnicas e princípios de auditoria financeira, aplicados à atividade acadêmica e de pesquisa. Estando orientadas por um plano de lutas contra a "precarização do trabalho e da formação profissional", vêm atuando em várias frentes.

Como resultado deste trabalho de denúncia e crítica, em agosto de 2009, por meio da Portaria n. 44, publicada no Diário Oficial da União, o MEC descredencia a Fundação Universidade de Tocantins (Unitins) para a oferta de cursos superiores na modalidade a distância. $\mathrm{O}$ descredenciamento da Unitins é uma vitória da categoria, mas, mais do que isso, constitui-se em uma vitória da população brasileira, que tem direito ao atendimento por profissionais qualificados. Nesse âmbito, sabe-se que há ainda uma luta árdua a ser enfrentada contra os que têm o poder de mando na educação superior no Brasil.

Como patrimônio histórico da categoria temos a construção de uma forte relação entre graduação e pós-graduação. Defendemos o princípio de que a formação pós-graduada deve oferecer subsídios à graduação, e esta deverá fornecer os objetos que deverão ser aprofundados na pós-graduação. Essa relação se expressa na existência de núcleos e grupos de pesquisa consolidados na área, que envolvem a graduação e a pós-graduação, numa produção que tem sido reconhecida nacional e internacionalmente.

No campo da pesquisa, temos muito que superar: a área, apesar do seu reconhecimento como produtora de conhecimento desde os anos 1980, bem como de possuidora de diversos programas de pós-graduação consolidados, 
encontra limites para concorrer aos editais das agências de fomento, uma vez que, em sua maioria, eles se destinam às áreas tecnológicas ou da saúde.

Poucos são os intercâmbios e convênios entre os programas e núcleos/ grupos de pesquisa. Algumas poucas iniciativas, mas exitosas, têm sido realizadas por meio do Programa Nacional de Cooperação Acadêmica (Procad) e de alguns convênios de Mestrado Interinstitucional (Minter).

Apesar de a produção brasileira na área ser muito requisitada por outros países da América Latina, temos dificuldade na sua circulação e possuímos raras experiências de convênios internacionais.

Cabe mencionar que dadas às condições sob as quais o trabalho docente se realiza - em especial nas instituições privadas, tais como contrato de trabalho horista, ausência de espaço físico, ausência de investimento institucional, dentre outras - , a pesquisa fica comprometida ou é resultado da iniciativa individual do docente. ${ }^{18}$

Considerando a sua natureza interventiva, a área tem sido pressionada a oferecer cursos de mestrado profissional. Já é realidade a entrada dos mestrados multiprofissionais para profissões da saúde, na qual se insere o Serviço Social.

No campo das condições de trabalho, não é casual que as entidades da categoria tenham investido, com muito sucesso, na defesa das condições éticas e técnicas, da qual a supervisão é parte integrante e na definição de uma política nacional de estágio/supervisão. Estas foram as conquistas mais importantes dos últimos anos.

Mas ainda temos grandes desafios. Em primeiro lugar, entendo que a formação profissional tem que se livrar de seus vícios tradicionais: o tecnicismo, o teoricismo e o militantismo.

É importante chamar a atenção, como faz Netto (1996, p. 110), que tem havido uma mudança significativa no perfil dos alunos "cada vez mais recrutado em estratos médio-baixos das camadas urbanas", constituindo-se hoje em trabalhadores que estudam, trazendo "um visível empobrecimento do universo cultural". O mesmo vem acontecendo com os docentes, pois dada a precarização da formação e das condições de trabalho, o perfil de docente tem se modi-

18. Chamo a atenção para o fato de que esta situação encontra-se amplamente apoiada na legislação educacional, que cria categorias de instituições universitárias: as universidades, as faculdades e os centros universitários, gerando a possibilidade legal de estes últimos não habilitarem seus quadros para desenvolver pesquisa. 
ficado de forma considerável. Há uma profunda pauperização da classe trabalhadora, o que reflete também no empobrecimento cultural da mesma.

Cabe à Abepss pautar uma discussão profunda sobre os critérios de avaliação, especialmente, mas não exclusivamente, do Sinaes, bem como fornecer subsídios para o debate sobre produtividade, entendida como produção de qualidade versus produtivismo acadêmico, que se identifica com os processos fordista/taylorista de produção.

Na contramão do mercado, o Serviço Social tem orientado, no campo da pesquisa, temas que vão ao encontro dos interesses da classe trabalhadora. Neste aspecto, registra-se o esforço de organizar a produção da área por meio da constituição dos Grupos Temáticos de Pesquisa (GTPs), considerados como estratégia de contraposição aos critérios estranhos às ciências humanas e sociais. Os GTPs "têm como finalidade alimentar o debate da formação e do exercício profissionais e as publicações da área, estimular a organização de redes de pesquisa, fomentar a articulação das pesquisa desenvolvidas nas universidades e instituições de pesquisa na América Latina e em outros continentes" (Abepss, 2009). Há que se buscar estratégias que fortaleçam vínculos entre pesquisadores, temáticas e demandas concretas da população. A dimensão investigativa tem que ser assumida como uma competência profissional e a pesquisa como indispensável à consolidação da área como produtora de conhecimento que tenha uma relevância social.

Considero que toda esta análise tem que ser levada em conta neste período eleitoral, na escolha dos nossos candidatos. Os últimos dois governos FHC e Lula, e especialmente o último, aprofunda a reforma regressiva na educação superior no Brasil. Enfrentar a lógica predatória da formação de qualidade, associada às lutas em curso, tais como pelo PLC n. 152 por trinta horas de trabalho sem prejuízo do salário e pelo estabelecimento de piso salarial, colocam nossas entidades como interlocutores dos partidos políticos e candidatos. As nossas entidades organizativas têm este papel e não apenas não se furtam a ele, mas o realizam com competência teórica e política.

Há que se buscar as alternativas que construam outro projeto de sociedade para o Brasil, cabendo à categoria manter-se não apenas no enfrentamento da ofensiva do mercado e na defesa da educação pública, universal, gratuita, laica e socialmente relevante, mas, fundamentalmente, contra a barbárie capitalista.

\section{Artigo recebido em ago./2010 - Aprovado em ago./2010}




\section{Referências bibliográficas}

ABEPSS. A consolidação da Abepss como organização acadêmico-científica. Documento base de discussão para a formação dos Grupos Temáticos de pesquisa (GTPs), 2009. Disponível em: <http://www.abepss.org.br/documentos.php>. Acesso em: 10 maio 2010 .

ALVES, Giovanni. O novo (e precário) mundo do trabalho: reestruturação produtiva e crise do sindicalismo. São Paulo: Boitempo/Fapesp, 2000.

. Trabalho e mundialização do capital: a nova degradação do trabalho na era da globalização. Londrina: Praxis, 1999.

ANDES. Sindicato nacional: expansão das Ifes: nota pública do Andes-SN. Disponível em: < http://www.andes.org.br/imprensa/Uploads/Circ022-06.pdf>. Acesso em: 10 maio 2010 .

ANTUNES, Ricardo. Adeus ao trabalho: ensaio sobre as metamorfoses e a centralidade do mundo do trabalho. São Paulo: Cortez, 1995.

. Dimensões da crise e as metamorfoses do mundo do trabalho. Serviço Social \& Sociedade, São Paulo, ano XVII, n. 50, abr. 1996.

BRESSER PEREIRA, Luís Carlos. Crise econômica e reforma do Estado no Brasil: para uma interpretação da América Latina. São Paulo: Ed. 34, 1996.

BUARQUE, Cristovam. Universidade numa encruzilhada. Unesco: Ministério da Educação, 2003.

CHAUI, Marilena. A universidade operacional. Folha de S.Paulo, caderno Mais!, 9 maio 1999. Disponível em: <http://www.cacos.ufpr.br/obras/Marilena_Chaui_Universidade_Operacional.doc $>$. Acesso em: 5 maio 2010.

. A universidade pública sob nova perspectiva. Faculdade de Filosofia, Letras e Ciências Humanas da Universidade de São Paulo. Conferência de abertura da $26^{a}$ Reunião Anual da Anped, Poços de Caldas/MG, 5 out. 2003. Disponível em: <http:// www.artnet.com.br/ apesjf/unipub.html>. Acesso em: 11 maio 2010.

CHESNAIS, François. A mundialização do capital. São Paulo: Xamã, 1996.

DRUCK, Graça. Flexibilização e precarização: formas contemporâneas de dominação do trabalho - Introdução. Caderno CRH, Salvador, n. 37, jul./dez. 2002.

; FILGUERIAS, L. Política social focalizada e ajuste fiscal: as duas faces do governo Lula. Revista Katálysis, Florianópolis, v.10, n. 1, 2007. 
HARVEY, David. Condição pós-moderna. Trad. Adail Ubirajara Sobral e Maria Stela Gonçalves. São Paulo: Loyola, 1994.

LEHER, Roberto. Reforma Universitária do governo Lula: retorno do protagonismo do Banco Mundial e das lutas antineoliberais. 6 fev., 2004. Disponível em: $<$ http://www. adur-rj.org.br/5com/pop-up/Reforma_universit_governo_LULA.htm>. Acesso em: 10 maio 2010.

MATTOSSO, Jorge. A desordem do trabalho. 1. reimpr. São Paulo: Pagina Aberta-Scritta, 1996.

MEC. Portaria Normativa n. 7, de 22 de junho de 2009. Disponível em: $<$ http://www. unb.br/administracao/decanatos/dpp/legislacao/Portaria_Normativa_N_07_de_22_de_ junho_de_2009.pdf>. Acesso em: 10 maio 2010.

NETTO, José P. Transformações societárias e Serviço Social: notas para uma análise prospectiva da profissão. Serviço Social \& Sociedade, São Paulo, ano XVII, n. 50, p. 87-132, abr. 1996.

OTRANTO, Celia R. Desvendando a política da educação superior do governo Lula. Universidade e Sociedade, Brasília, ano XVI, n. 38, p. 18-29, jun. 2006. Disponível em: < http://www.celia.na-web.net/pasta1/trabalho14.htm>. Acesso em: 10 maio 2010.

SILVA, Denise V. Alienação no trabalho docente? O professor no centro da contradição. Tese (Doutorado em Ciências Sociais) — Universidade Federal da Bahia, Salvador, 2007.

SILVA JR., João dos Reis; SGUISSARDI, Valdemar. Novas faces da educação superior no Brasil: reforma no Estado e mudança na produção. Bragança Paulista: Edusf, 1999.

VIEIRA, Evaldo. As políticas sociais e os direitos sociais no Brasil: avanços e retrocessos. Serviço Social \& Sociedade, São Paulo, ano XVIII, n. 53, 1997.

VV. AA. Serviço Social \& Sociedade, São Paulo, ano XVII, n. 50, 1996.

WACQUANT, Loïc. As prisões da miséria. Rio de Janeiro: Jorge Zahar, 2001.

. Entrevista com Loïc Wacquant: A criminalização da pobreza. Mais Humana, dez. 1999. Disponível em: <www.maishumana.com.br/loic1.htm>. Acesso em: 10 maio 2010. 